\title{
Produção de Enzimas Extracelulares por Crinipellis perniciosa
}

\author{
Cleber N. Bastos \\ CEPLAC/SUPOR/ERJOH, Cx. Postal 46, CEP 67105-970, Marituba, PA, e-mail: cleber@ufpa.br
}

(Aceito para publicação em 06/04/2004)

BASTOS, C.N. Produção de enzimas extracelulares por Crinipellis perniciosa. Fitopatologia Brasileira 30:286-288. 2005.

\begin{abstract}
RESUMO
Isolados de Crinipellis perniciosa, obtidos a partir de cacaueiro (Theobromae cacao), cupuaçuzeiro (T. grandiflorum) e solanáceas silvestres foram testados quanto à capacidade de produzirem enzimas extracelulares que degradam celulose, amido, lipídios e lignina. A produção de todas as enzimas foi determinada em meios sólidos e representada por uma estimativa, baseada na intensidade de cor, ou pela avaliação do diâmetro dos halos formado nos meios. Foi detectada variabilidade entre os isolados na capacidade de produzir enzimas celulolíticas, amilases, lipases, polifenol-oxidases, peroxidases e esterases. Quanto às enzimas proteolíticas, todos os isolados apresentaram alto nível de atividade, não sendo observada diferença no comportamento entre eles. Por outro lado, nenhum dos isolados produziu pectinase, urease e fosfatase-ácida. Os papéis das enzimas líticas produzidas pelos isolados de $C$. perniciosa na patogênese e na produção de basidiomas são discutidos
\end{abstract}

Palavras-chave adicionais: Theobromae cacao, T. grandiflorum, variabilidade, solanáceas.

\begin{abstract}
Production of extracellular enzymes by Crinipellis perniciosa

Strains of Crinipellis perniciosa isolated from cocoa (Theobromae cacao), cupuassu (T. grandiflorum) and wild solanaceous were tested for their ability to produce extracellular enzymes which degrade cellulose, starch, lipids and lignin. The production of all enzymes was examined in solid media and was estimated based on the intensity of color or on the diameter of halos formed on the media. Variability was detected among the isolates in their capacity to produce cellulolytic enzymes, amylase, lypase, phenol-oxidase, peroxidase and esterase. All isolates presented high level of activity, regarding proteolytic enzymes. On the other hand, none of the isolates produced pectinase, urease and acid phosphatase. The roles of lytic enzymes of $C$. perniciosa on pathogenesis and on basidiome production are discussed.
\end{abstract}

Additional keywords: Theobromae cacao, T. grandiflorum, variability, solanaceus.

O fungo Crinipellis perniciosa (Stahel) Singer é o agente causal da vassoura-de-bruxa do cacaueiro (Theobroma cacao L.), do cupuaçuzeiro (Theobroma grandiflorum (Willd. Ex Spreng.), de solanáceas e de outros hospedeiros.

A ecologia do fungo e a epidemiologia da doença são bem documentadas (Rocha \& Wheeler, 1985) e vários aspectos da interação hospedeiro-patógeno, incluindo mecanismo de infecção, incidência e virulência de patótipos (Evans, 1978); avaliação de métodos para testar resistência em cultivares de cacau (Evans \& Bastos, 1980); avaliação de potenciais métodos para controle biológico (Bastos, 1988), controle cultural (Bastos \& Evans, 1979) e controle químico (Bastos, 1989). Entretanto, a capacidade do fungo de produzir enzimas extracelulares não tem sido investigada em detalhes, exceto para lacases e peroxidades (Krupasagar \& Sequeira, 1969).

Este trabalho relata os resultados de um screening para se verificar a produção de enzimas por isolados de $C$. perniciosa, provenientes de cacaueiro, cupuaçuzeiro e das solanáceas silvestres, Solanum rugosum (Dun.) e Athanaea aff pogogena (Moric) Sendth.

As culturas de C. perniciosa (Tabela 1) foram obtidas a partir de vassouras vegetativas verdes dos hospedeiros e mantidas a $25-27{ }^{\circ} \mathrm{C}$ em tubos de ensaio contendo BDA, através de repicagens sucessivas. Fragmentos de micélio foram transferidos para placas de Petri contendo extrato de malte- ágar (EMA), incubadas a $25^{\circ} \mathrm{C}$, na ausência de luz durante seis-oito dias, para a obtenção dos inóculos para os testes enzimáticos.

A produção de amilases foi determinada no meio nutriente-ágar (Difco) contendo 0,2\% de amido solúvel (Merck) como descrita por Coon et al. (1957). A produção de polifenol-oxidases foi determinada de acordo com o método de Nobles (1958). A atividade celulolítica foi avaliada conforme Lewis (1988), usando um meio de sais mineraiságar (Tuite, 1969) suplementado com celulose Whatman $n^{\circ} 1$ ou carboximetil-celulose para produção de celulase e carboximetil celulase, respectivamente. Para detectar atividade pectolítica foi empregado o método descrito por Hankin et al., (1971). A produção de lipases foi avaliada no meio de Sierra (1957), usando Tween 80 como substrato. A produção de proteases foi determinada pelo método descrito por Smibert \& Krieg (1981). A produção das enzimas fosfatase - ácida e esterase foi determinada segundo Taylor (1974) e urease conforme Seeliger (1956). Todos os testes foram conduzidos em placas de Petri de $9 \mathrm{~cm}$ de diâmetro contendo $15 \mathrm{ml}$ do meio teste. No centro de cada placa foi depositado um disco de micélio de $5 \mathrm{~mm}$ de diâmetro, retirado de colônias das culturas de $C$. perniciosa e, em seguida, todas as placas foram incubadas a $25^{\circ} \mathrm{C}$, na ausência de luz. Como testemunha, foram usadas placas apenas com discos de meio de cultura 
TABELA 1 - Isolados de Crinipellis perniciosa utilizados nos testes enzimáticos, hospedeiros e locais de coleta

\begin{tabular}{llll}
\hline \hline \multicolumn{2}{l}{ Isolado } & Hospedeiro & Local \\
\hline Cp & 01 & Theobroma cacao & Benevides - PA \\
Cp & 02 & T. cacao & Benevides - PA \\
Cp & 03 & T. cacao & Belém - PA \\
Cp & 07 & T. grandiflorum & Benevides - PA \\
Cp & 08 & T. grandiflorum & Tomé-Açu - PA \\
Cp & 011 & T. grandiflorum & Castanhal - PA \\
Cp & 015 & Athanaea aff pogogena ${ }^{*}$ & Arataca - BA \\
Cp & 017 & Solanum rugosum & Manaus - AM \\
\hline * Solanăcea
\end{tabular}

* Solanáceas silvestres

sem o fungo. A produção das enzimas proteases, celulases, polifenol-oxidases, amilases, lipases e esterases foi determinada através da mensuração do diâmetro do halo formado em torno das colônias, representada pela seguinte escala: 0 , não produção de enzima; 1 , diâmetro do halo entre $1-5 \mathrm{~mm}$; 2 , diâmetro entre 5-10 mm; 3, diâmetro entre 10-20 mm; 4, diâmetro entre 20-30 mm; e 5, diâmetro superior a $30 \mathrm{~mm}$. No caso de urease, peroxidase, pectinase e fosfatase-ácida usou-se símbolos que representam uma estimativa subjetiva da produção das enzimas, baseada na intensidade da coloração formada no meio: +++ intensa; ++ moderada; + fraca; e - ausência. Em todos os casos, foram empregadas três repetições para cada combinação enzima e isolado.

A produção de enzimas proteases foi detectada para todos os isolados do fungo (Tabela 2) e pode ser atribuída como uma característica da espécie. A atividade celulolítica, embora em níveis variáveis, foi detectada para todos os isolados, quando celulose Whatman foi usada como substrato. Contudo, nenhum dos isolados demonstrou atividade para degradar carboximetilcelulose (dados não mostrados).

A reação foi considerada positiva para produção de peroxidases quando ocorreu formação de halo de coloração amarelo-ouro em volta da colônia do fungo. Observou-se que $\mathrm{Cp}-07$ e Cp-011, ambos isolados de cupuaçuzeiro, apresentaram uma reação mais forte que os demais e, os isolados Cp-015, (isolado de A. aff pogogena), $\mathrm{Cp}-017$ (isolado de S. rugosum) e Cp-08 (isolado de cupuaçuzeiro) apresentaram reações muito fracas (Tabela 2). A atividade de fenol-oxidases, um suposto teste para avaliar a habilidade do fungo em degradar lignina, foi determinada usando-se ácido gálico como substrato. Os isolados exibiram uma variabilidade na produção dessa enzima. Não foi detectada presença de polifenol-oxidases nos testes com os isolados Cp-01 e Cp-08 (Tabela 2). As fenoloxidases que têm sido encontradas em himenomicetos pertencem a dois tipos de enzimas: tirosinases e lacases. Krupasagar \& Sequeira (1969) demonstraram que $C$. perniciosa produz em meio de cultura duas diferentes oxidases: uma peroxidase semelhante à oxidase do ácido indol- acético (AIA) e uma oxidase (lacase), que é também produzida por outros basidiomicetos. Entretanto, Laker (1987), objetivando detectar diferenças entre isolados de $C$. perniciosa, procedentes de diferentes regiões em Trinidad, com base na produção de peroxidase e lacase, verificou que a lacase não foi produzida em todos os isolados.

A capacidade de fenol-oxidases em destruir auxinas pode ser significante na patogênese por $C$. perniciosa (Krupasagar $\&$ Sequeira, 1969). Ramos de cacau infetados pelo fungo exibem perda de dominância apical e proliferação de gemas axilares. É possível que o micélio intracelular saprofítico libere oxidases capazes de reduzir a concentração de ácido giberélico e ácido indol-acético (AIA), provocando um desequilíbrio no sistema hormonal do ramo foliar infetado.

A produção de amilases foi detectada em meio contendo amido solúvel. Apenas os isolados Cp-01, Cp-02 e Cp-08 não apresentaram atividade amilolítica. Em relação à produção de lipase, observou-se que todos os isolados de C. perniciosa apresentaram atividade lipolítica. Atividades enzimáticas para pectinases, ureases e fosfatase-ácidas não foram detectadas a partir dos isolados testados. Por outro lado, com execeção de $\mathrm{Cp}-08$, todos os demais isolados apresentaram atividade para esterases (Tabela 2).

Pelos resultados obtidos, sugere-se que $C$. perniciosa tem a capacidade de utilizar celulose, amido e lipídios como fontes de energia. Também, admite-se que, durante o período de incubação no hospedeiro o fungo libera enzimas (amilases, celulases, proteases e oxidases) que ativamente degradam os

TABELA 2 - Produção de enzimas extracelulares por isolados de Crinipellis perniciosa em meios de cultura sólidos

\begin{tabular}{|c|c|c|c|c|c|c|c|c|c|c|}
\hline $\begin{array}{l}\text { Isolado de } \\
\text { Crinipellis perniciosa }\end{array}$ & Protease* $^{*}$ & Celulase & $\begin{array}{l}\text { Polifenol } \\
\text { oxidase }\end{array}$ & Amilase & Lipase & Esterase & Peroxidase $^{* *}$ & Pectinase & Urease & $\begin{array}{c}\text { Fosfatase } \\
\text { ácida }\end{array}$ \\
\hline $\mathrm{Cp}-01$ & 5 & 3 & 0 & 0 & 1 & 3 & ++ & - & - & - \\
\hline $\mathrm{Cp}-02$ & 5 & 3 & 4 & 0 & 2 & 3 & ++ & - & - & - \\
\hline $\mathrm{Cp}-03$ & 5 & 4 & 3 & 4 & 1 & 3 & ++ & - & - & - \\
\hline $\mathrm{Cp}-07$ & 5 & 4 & 2 & 5 & 1 & 3 & +++ & - & - & - \\
\hline $\mathrm{Cp}-08$ & 3 & 3 & 0 & 0 & 2 & 0 & + & - & - & - \\
\hline $\mathrm{Cp}-011$ & 4 & 4 & 2 & 4 & 2 & 3 & +++ & - & - & - \\
\hline Cp-015 & 5 & 4 & 3 & 4 & 2 & 3 & + & - & - & - \\
\hline $\mathrm{Cp}-017$ & 5 & 4 & 3 & 4 & 2 & 3 & + & - & - & - \\
\hline
\end{tabular}

* A produção de proteases, celulases, polifenol-oxidases, amilases, lipases e esterases foi avaliada pela média (três repetições) do diâmetro do halo formado em torno das colônias, conforme a escala: 0 , não produção de enzima; 1 , diâmetro do halo entre 1-5 mm; 2, diâmetro entre 5-10 mm; 3, diâmetro entre 10-20 mm; 4, diâmetro entre $20-30 \mathrm{~mm}$; e, 5 , diâmetro superior a $30 \mathrm{~mm}$.

** A produção de peroxidases, pectinases, ureases e fosfatase-ácidas baseou-se na intensidade da cor resultante no meio, onde: coloração intensa +++; coloração moderada ++; coloração fraca + e ausência de coloração. 
componentes presentes no tecido infetado do hospedeiro. E, gradualmente, as quantidades de açúcares simples e aminoácidos aumentam, sendo, posteriormente, usados como fontes de carbono na produção de basidiomas.

A análise comparativa da produção de enzimas extracelulares, detectou variabilidade entre isolados de $C$. pernicios $a$, o que pode tornar de grande utilidade, ampliando o nível de esclarecimento na identidade e variabilidade do patógeno

\section{REFERÊNCIAS BIBLIOGRÁFICAS}

BASTOS, C.N. Resultados preliminares sobre eficácia de Trichoderma viride no controle da vassoura-de-bruxa (Crinipellis perniciosa) do cacaueiro. Fitopatologia Brasileira 13:340-342. 1988.

BASTOS, C.N. Avaliação de fungicidas sistêmicos no controle da vassoura-de-bruxa do cacaueiro. Agrotrópica 1:128-132. 1989.

BASTOS, C.N. \& EVANS, H.C. Resultados preliminares sobre o estabelecimento de um sistema de controle da vassoura-de-bruxa na Amazônia. Belém: CEPLAC/DEPEA/ASTEA. Comunicado Técnico $\mathrm{n}^{\circ} 12.1979$.

COON, H.J., JENNISON, M.W. \& WEEK, O.B. Routine tests for the identification of bacteria. In: Manual of Microbiological Methods (ed. Society of American Bacteriologists). New York. McGraw-Hal. 1957. pp.239-262.

EVANS, H.C. Witches' broom disease of cocoa (Crinipellis perniciosa) in Ecuador. I. The fungus. Annals of Applied Biology 89:185-192. 1978.

EVANS, H.C. \& BASTOS, C.N. Basidiospore germination as a means of assessing resistance to Crinipellis perniciosa (Witches' broom disease) in cocoa cultivars. Transactions of the British Mycological Society 74:523-536. 1980.

HANKIN, L., ZUCHER, M. \& SANDS, D.C. Improved solid medium for detection and enumeration of pectolytic bacteria. Applied Microbiology 22:205-209. 1971.
KRUPASAGAR, V. \& SEQUEIRA, L. Auxin destruction by Marasmius peniciosus. American Journal of Botany 56:390-397. 1969.

LAKER, H.A. Studies on pathogenic variability of Crinipellis peniciosa (Stahel) Singer in Trinidad. PhD Thesis. Trinidad. The University of West Indies. 1987.

LEWIS, K.J. Biological control mechanism of the mycoparasite Phytium oligandum Dreschler. PhD Thesis. Sheffield. University of Sheffield. 1988.

LINDEBERG, G. \& HOLM, G. Occurrence of tyrosinase and laccase in fruit bodies and mycelia of some hymenomycetes. Physiological Plantarum 5:100-114. 1952.

NOBLES, M.K. A rapid test for extracellular oxidase in cultures of wood-inhabiting Hymenomycetes. Canadian Journal of Botany 36:91-99. 1958.

ROCHA, H.M. \& WHEELER, B.E.J. Factors influencing the production of basidiocarps and the deposition and germination of basidiospores of Crinipellis perniciosa, the causal agent fungus of witches'broom on cocoa (Theobroma cacao). Plant Phatology 34:319-328. 1985.

SEELIGER, H.P.R. Use of a urease test for the screening and identification of Cryptococci. Journal of Bacteriology 72:127-131. 1956.

SIERRA, S.A. Simple method for detection of lipolytic activity of microorganisms and some observations on the influence of the contact between cells and fatty substrates. Antonie van Laeuwenhoek 23:15-22. 1957.

SMIBERT, R.M. \& KRIEG, N.R. General characterization. In: Gerhart, P. (Ed.) Manual of Methods of General Bacteriology. American Society of Microbiology. New York. 1981. pp.409-443.

TAYLOR, J.B. Biochemical test for identification of mycelial cultures of basidiomycetes. Annals of Applied Biology 78:113-123. 1974.

TUITE, J. Plant Pathotological Methods: Fungi and Bacteria. Minneapolis. Burgess Publishing Company. 1969. 